\title{
Structural, magnetic and optical studies of nickel ferrite thin films
}

\author{
Gagan Dixit $^{{ }^{\star}}$, J.P. Singh ${ }^{1}$, R.C. Srivastava ${ }^{1}$, H.M. Agrawal ${ }^{1}$, R.J. Chaudhary ${ }^{2}$ \\ ${ }^{I}$ Department of Physics, G. B. Pant Univ. of Agriculture \& Technology, Pantnagar, Uttarakhand 263145, India \\ ${ }^{2}$ UGC-DAE CSR, DAVV Campus, Khandwa Road, Indore 452017, India
}

*Corresponding author. E-mail: gagandikshit@yahoo.in

Received: 28 June 2011, Revised: 06 Sept 2011 and Accepted: 11 Sept 2011

\section{ABSTRACT}

In the present work, structural, morphological, magnetic and optical properties of nickel ferrite thin films having different thickness are reported. All the films were deposited on Si (100) substrate by pulsed laser deposition technique. Thicknesses of the films determined by x-ray reflectivity vary from 62 to $176 \mathrm{~nm}$ as the deposition time varies from $16 \mathrm{~min}$ to $40 \mathrm{~min}$. The films were characterised by x-ray diffractogram, Fourier transform infrared (FTIR) and Raman spectroscopy for structural and phase confirmation. FTIR and Raman spectra confirm mixed spinel nature of nickel ferrite. Surface morphology is studied by Atomic force microscopy. All the films have granular nature. Magnetic properties were studied by vibrating sample magnetometer and magnetic hysteresis curves were recorded for all the films at room temperature and at $10 \mathrm{~K}$. At $10 \mathrm{~K}$, saturation magnetisation was found to increase while coercivity deceases with thickness. The results are explained on the basis of anisotropy induced by cation inversion and strain. Optical properties were studied by UV-vis reflectance spectra. The value of optical band gap $(5.7 \mathrm{eV})$ was found to be independent of thickness of the film. Copyright (C) 2011 VBRI press.

Keywords: Nickel Ferrite, PLD, FTIR, Raman, VSM, UV- vis spectroscopy

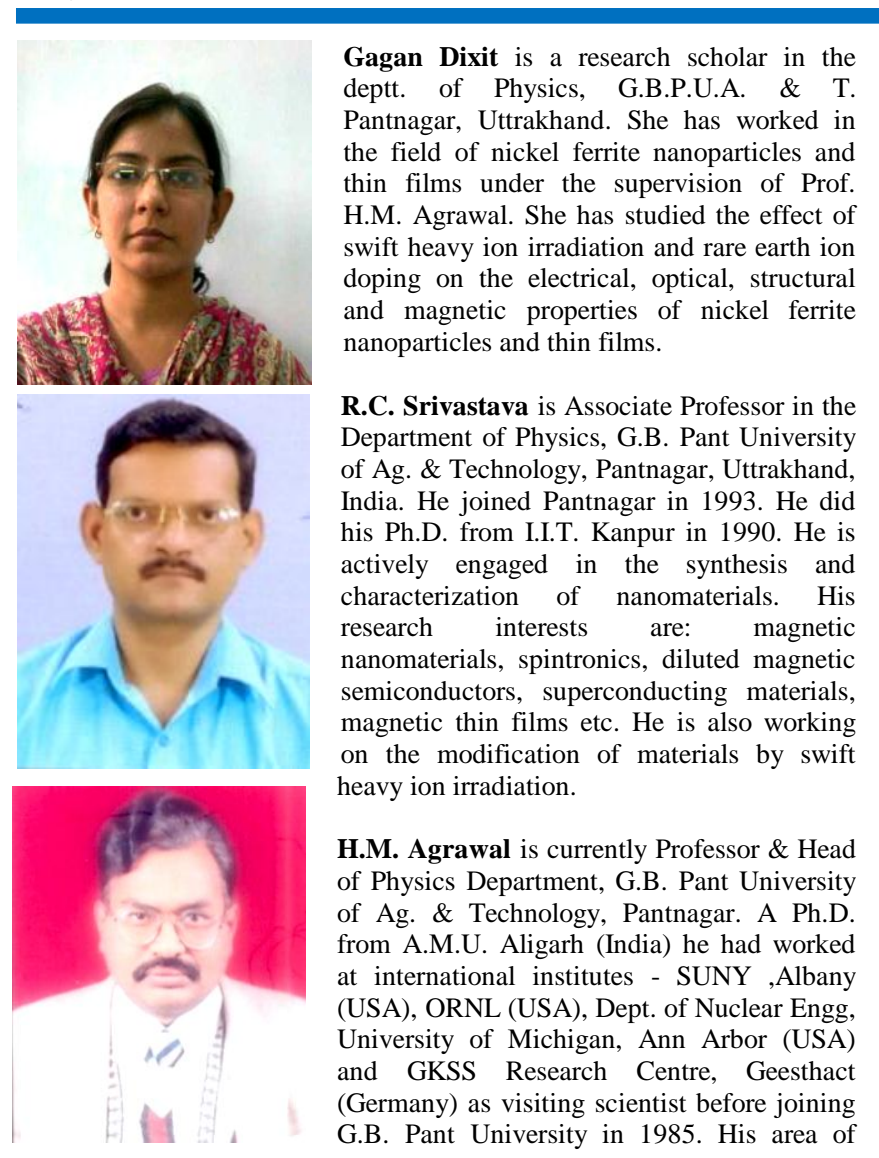

research interests are experimental nuclear Physics and material science. Since 2008 , he is guiding graduate students in the area of nanoscience $\mathrm{He}$ has over eighty publications in international/national journals to his credit.

\section{Introduction}

Ferrites are useful magnetic materials because of their versatility, low cost, and high electromagnetic performance over a wide frequency range. In order to readily integrate ferrites into electronic devices, it is desirable to fabricate thin film of these materials. Soft magnetic thin films with high electrical resistivity are needed for developing micro inductors and micro transformers, monolithic microwave integrated circuits etc [1]. Microstructure of thin film is an important parameter in determining their magnetic properties. There are various growth parameters that affect the microstructure of the film such as substrate temperature during deposition, thermal expansion coefficient and lattice mismatch between the film and substrate, deposition time, distance between the target and substrate etc. Size and surface effects lead to strong deviations from bulk properties, which additionally depend on the sample thickness and stoichiometry. However, the stoichiometry and structure of the surface and interface layers may differ from that of the film interior leading to different properties of the films having different thickness. This motivated us to 
study the effect of thickness on the properties of nickel ferrite thin films.

$\mathrm{NiFe}_{2} \mathrm{O}_{4}$ is one of the important ferrites used for different technological applications and as a humidity sensor also [2]. It crystallizes in inverse spinel structure i.e. tetrahedral sites are occupied by ferric ions and the octahedral sites by ferric and nickel ions. There are a number of deposition techniques available for spinel ferrite thin film fabrication as pulsed laser deposition (PLD) [3, 4], sputtering [5, 6], and e-beam reactive evaporation [7]. In the present work, thin films of nickel ferrite were deposited by PLD, because it retains the stoichiometry of the target in the film [8].There are reports on the effect of substrate [9], effect of annealing temperature $[\mathbf{1 0}, \mathbf{1 1}]$ on the microstructure and hence on the magnetic properties of the thin films of nickel ferrite. U.Luders et al [12] have studied the effect of thickness on ultra thin films $(3-6 \mathrm{~nm})$ of nickel ferrite. They observed that ultra thin films show very large magnetic moment in comparison to bulk. They attributed it to the anomalous distribution of $\mathrm{Fe}$ and $\mathrm{Ni}$ ions between tetrahedral and octahedral sites in ultra thin films. There are very few reports $[\mathbf{1 3}, \mathbf{1 4}]$ available related to the optical study of nanoparticles or thin films of nickel ferrite. Present work is motivated to study the effect of thickness $(80-200 \mathrm{~nm})$ on structural, magnetic and optical properties of nickel ferrite thin films.

\section{Experimental}

Nanopowder of $\mathrm{NiFe}_{2} \mathrm{O}_{4}$ was synthesized by using the nitrates of nickel and iron along with citric acid as the host [15]. The molar ratio of cations to citric acid was kept 1:2. The powder thus obtained was pressed in the pellet form by hydraulic press. The pellet was sintered at $1200^{\circ} \mathrm{C}$ for $3 \mathrm{~h}$.The substrate used for film deposition was Si (100) of size $10 \times 10 \mathrm{~mm}$. A Lambda Physik $\mathrm{KrF}$ excimer laser of wavelength $248 \mathrm{~nm}$ was used for deposition. Pulse energy was $220 \mathrm{~mJ}$, pulse duration $20 \mathrm{~ns}$, and repetition rate was kept $10 \mathrm{~Hz}$. Base pressure in the chamber before deposition was $10^{-5}$ torr maintained by SD-200 Turbo V200 pump. The substrate was mounted at a distance of $4 \mathrm{~cm}$. from the target. The substrate temperature was kept $600^{\circ} \mathrm{C}$. In order to maintain the stoichiometry in the films, $\mathrm{O}_{2}$ gas was flowed during deposition under a pressure of 100 mtorr. To obtain the films of different thickness the deposition time was varied from 16-40 min. In order to minimize the occurrence of ferrite droplet due to splashing from target the deposition was done under constant energy of laser. The films were characterised by Rigaku-Japan make X-ray diffractometer (XRD) using $\mathrm{Cu}-\mathrm{K}_{\alpha}$ radiation for the confirmation of phase and structure. The films were characterised by X-ray refelectivity (XRR) measurement using Bruker Axs D8 Discover set-up, for the exact determination of thickness. To study the surface morphology atomic force microscopy (AFM) was carried out using Nanoscope E Digital instrument with a silicon nitride cantilever in contact mode. The tip radius of cantilever is $20 \mathrm{~nm}$ and force constant $0.56 \mathrm{~N} / \mathrm{m}$. To study the optical properties UV-Vis spectra were recorded by Perkin Elmer Lamda 950 spectrometer in the wavelength range 200-800 nm. Fourier Transform Infrared (FTIR) spectra of the films were recorded in the range 500-1000 $\mathrm{cm}^{-1}$ by Bruker Model Vertex 70 FTIR spectrophotometer. The films were characterised by Raman Spectroscopy for micro structural analysis. The micro-Raman system used in this study consisted of $200 \mathrm{~mW}$ Ar-ion laser (488 nm), single grating $0.5 \mathrm{~m}$ spectrometer, and charge - coupled device $(\mathrm{CCD})$ detector $(1100 \times 330$ pixels $)$, and holographic optics. The focal spot-size was $10-20 \mu \mathrm{m}$. A spectral range of $200-800 \mathrm{~cm}^{-1}$ was examined in this study using a 1800 grooves $/ \mathrm{mm}$ grating. The spectrometer was regularly calibrated using the Ar emission spectrum. A 10 minute exposure time was used for recording the Raman spectrum. Magnetic properties of the films were studied by using VSM Quantum design model 6000 PPMS and M-H measurements were done at room temperature and at $10 \mathrm{~K}$. The sensitivity of this set up is $10^{-6} \mathrm{emu}$.

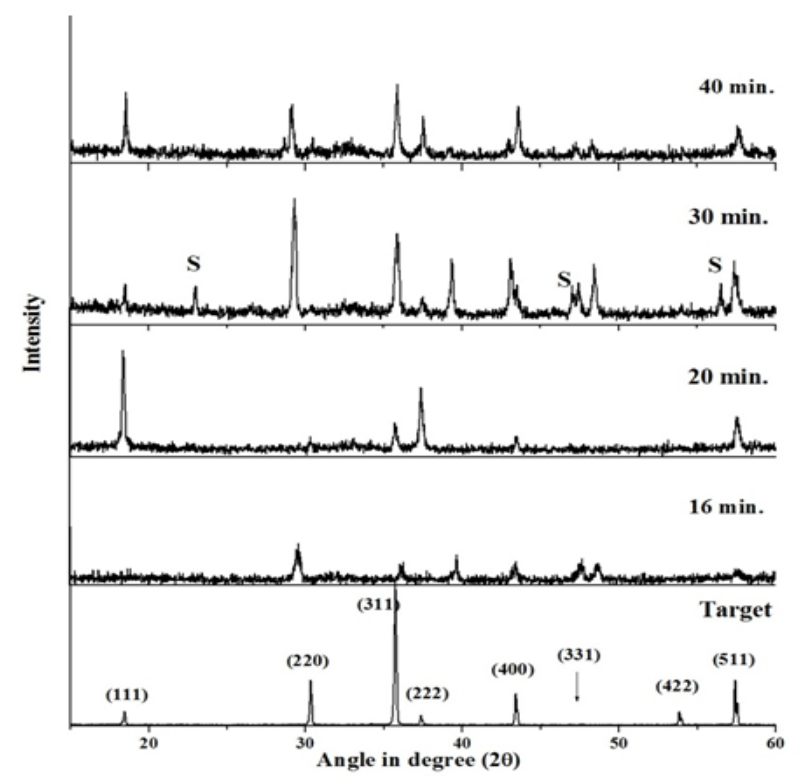

Fig. 1. XRD pattern for the target and films deposited for different time ( $\mathrm{S}$ stands for the peak of substrate).

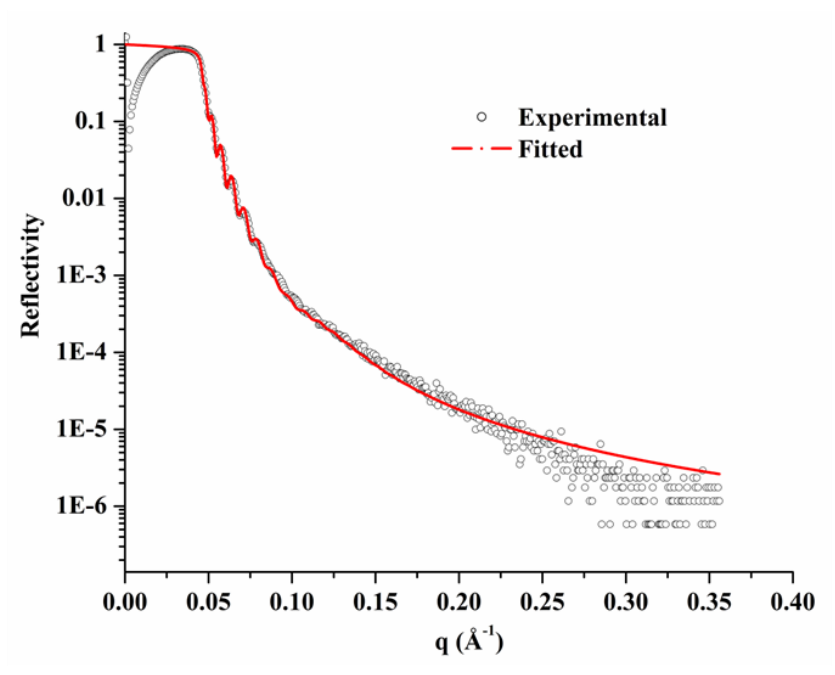

Fig. 2. XRR plot fitted for film of thickness $62 \mathrm{~nm}$. 


\section{Results and discussion}

\section{Structural Study}

Fig. 1 shows the XRD pattern of target and all the four films deposited for different time periods in the range 16-40 min. In the pattern $S$ indicates the substrate peak. The pattern confirms that the target has pure spinel phase of nickel ferrite (JCPDS-742081). The films also show spinel phase of nickel ferrite but there are some extra peaks appearing at $2 \theta$ values $\sim 39^{\circ}$ and $\sim 48^{\circ}$ in 16 and $30 \mathrm{~min}$. deposited films. These peaks appear in $40 \mathrm{~min}$. deposited film also, with very small intensity. These are the peaks of $\alpha-\mathrm{Fe}_{2} \mathrm{O}_{3}[\mathbf{1 6}, 17]$. The peak appearing at $\sim 29^{\circ}$ in 16,30 and 40 min deposited films, correspond to (220) peak of nickel ferrite phase [18], indicating a shifting towards lower angle. The 20 min deposited film corresponds to the pure phase of nickel ferrite without shifting or extra phase. All the films are polycrystalline in nature. For the determination of thickness and roughness of films, XRR was done and it was found that the films deposited for 16, 20, 30 and $40 \mathrm{~min}$ have thickness of $62,85,118$ and $176 \mathrm{~nm}$ respectively (Table 1).

Fig. 2 shows a representative XRR curve for the film of thickness $62 \mathrm{~nm}$. XRR curves were fitted by considering the $\mathrm{SiO}_{2}$ layer, as the $\mathrm{Si}$ substrate gets oxidized because of presence of $\mathrm{O}_{2}$ gas during deposition. Fig. 3 shows three dimensional AFM images of the films. AFM pictures show that all the films have granular nature. The droplet contamination which generally occurs in PLD deposited films $[\mathbf{1 9}, \mathbf{2 0}]$ is rare in the present case. The grain size and roughness as determined from AFM are given in Table 1. Roughness determined by XRR and AFM are almost comparable. Both the grain size and surface roughness increase with the increase in thickness of the films, though the average grain size of 62 and $87 \mathrm{~nm}$ thick film are almost same. Smooth surfaces are one of the prerequisites for low microwave loss [21], so the thickness of the films should be less for microwave application point of view. This is in accordance with the result obtained by other researchers [22].

\section{FTIR and Raman study}

Spinel type oxides of transition metals can be divided into two categories- normal and inverse. Nickel ferrite has inverse spinel structure, prototype symmetry $\mathrm{O}_{\mathrm{h}}{ }^{7}$ and spacgroup $F d 3 \mathrm{~m}$. Group theory predicts 42 vibrational modes corresponding to spinel structure [23]

$\mathrm{A}_{1} \mathrm{~g}(\mathrm{R})+\mathrm{Eg}(\mathrm{R})+\mathrm{T}_{1} \mathrm{~g}(\mathrm{in})+3 \mathrm{~T}_{2} \mathrm{~g}(\mathrm{R})+2 \mathrm{~A}_{2} \mathrm{u}($ in $)+2 \mathrm{Eu}$ (in) $+4 \mathrm{~T}_{1} \mathrm{u}$ (IR) $+2 \mathrm{~T}_{2} \mathrm{u}$ (in)

where R,IR and in represent Raman and infrared vibrations and inactive modes respectively. Thus there are four IR active bands in the spectral region $v_{1}\left(630-560 \mathrm{~cm}^{-1}\right), v_{2}$ $\left(525-390 \mathrm{~cm}^{-1}\right), v_{3}\left(380-335 \mathrm{~cm}^{-1}\right) v_{4}\left(300-200 \mathrm{~cm}^{-1}\right)$. Two of the bands found in far infra red region are not seen. The $v_{1} \& v_{2}$ bands are assigned to the vibrations of the tetrahedron and octahedron for the trivalent $\left(\mathrm{Fe}^{3+}\right)$ cation respectively. The $v_{3} \& v_{4}$ bands are affected to complex vibrations involving both octahedral and tetrahedral sites [24].

Table 1. Thickness, grain size and roughness of thin films deposited for different time durations.

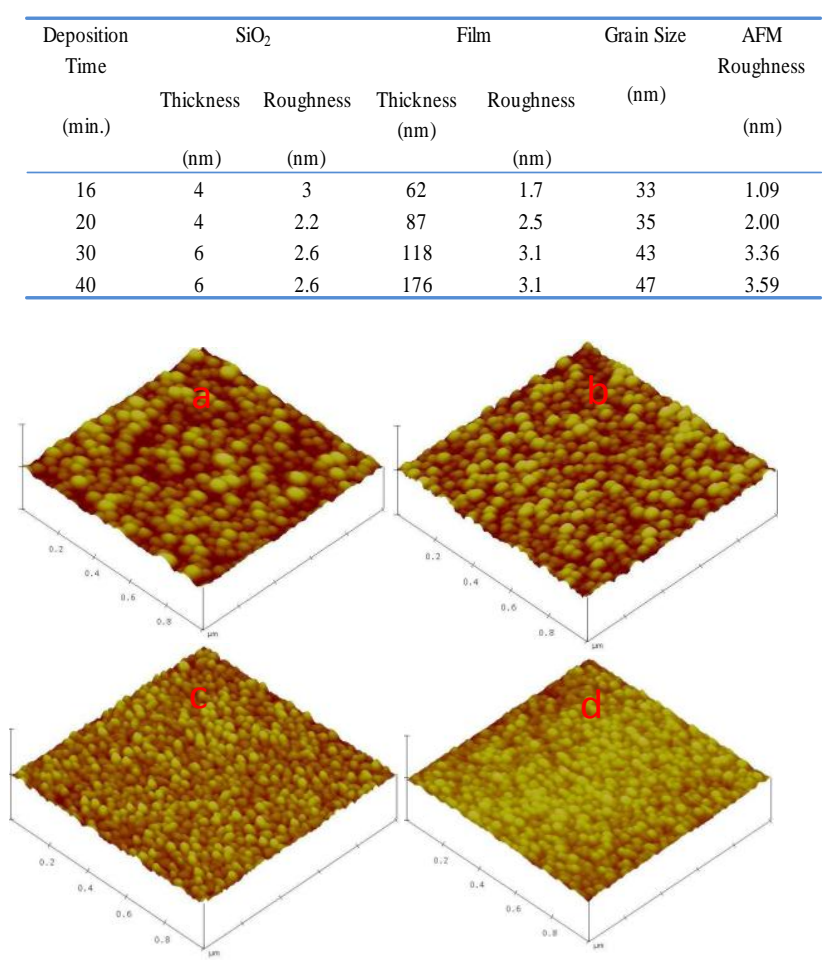

Fig. 3. AFM images of the films of thickness (a) 176 (b) 118 (c) 87 and (d) $62 \mathrm{~nm}$.

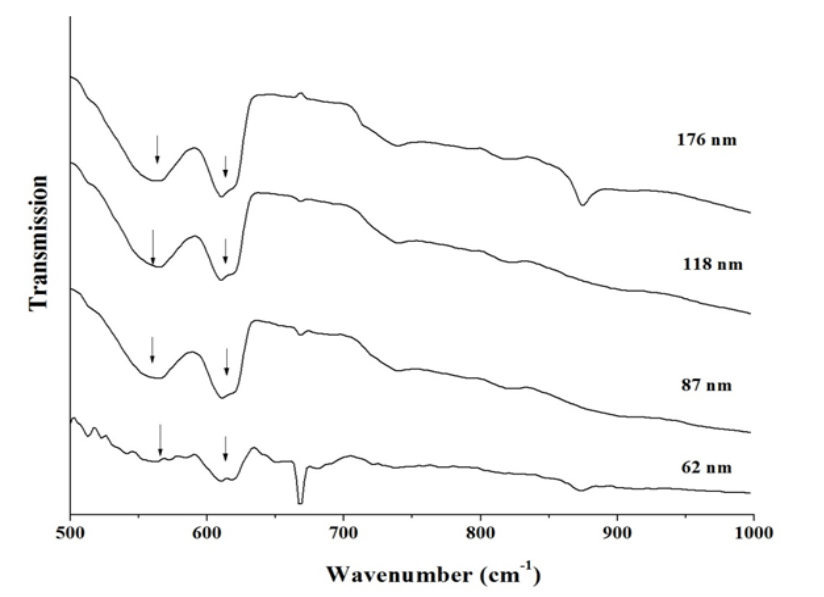

Fig. 4. FTIR spectra of the films of different thickness.

Fig. 4 shows the FTIR spectra of the films of different thickness. Presently there are two bands at 562 and $611 \mathrm{~cm}^{-}$ ${ }^{1}$. These are the sub-bands of tetrahedral site. The splitting of main tetrahedral band shows that some of the $\mathrm{Ni}^{+2}$ are shifted to tetrahedral site from octahedral site [25]. The difference in band positions for tetrahedral and octahedral complexes is due to the difference in values of $\mathrm{Fe}^{3+}-\mathrm{O}^{2-}$ band distances. There is kink at 667 and $819 \mathrm{~cm}^{-1}$ also. The $667 \mathrm{~cm}^{-1}$ is due to sample holder as confirmed by taking the spectrum of blank sample holder and $819 \mathrm{~cm}^{-1}$ is due to $\mathrm{Fe}-$ 
$\mathrm{O}-\mathrm{H}$ bonding [26]. From the plot it is observed that as the thickness of the films reduces the width of the bands increases. This shows that the particle size is reducing with thickness. To have more information regarding the structure of the films Raman spectra were recorded at room temperature and are shown in Fig. 5. The peaks appearing at $212,334,483,574$ and $702 \mathrm{~cm}^{-1}$ with a shoulder at 666 $\mathrm{cm}^{-1}$ are characteristic peaks of nickel ferrite $[27,28]$. The intense peak at $520 \mathrm{~cm}^{-1}$ corresponds to the substrate $\mathrm{Si}$ (100). The wave number position of the bands does not change significantly with thickness. Table 2 shows the peak position for all the four films with the assignment of bands. There is a peak at $306 \mathrm{~cm}^{-1}$ in film of thickness $62 \mathrm{~nm}$. This peak appears in films of thicknesses 87 and $118 \mathrm{~nm}$, also with very small intensity and disappears in $176 \mathrm{~nm}$ thick film. This corresponds to $\alpha-\mathrm{Fe}_{2} \mathrm{O}_{3}$ [29]. Raman peaks over the region of $660-720 \mathrm{~cm}^{-1}$ represent the modes of tetrahedral group (T-site) and those in the 460-660 $\mathrm{cm}^{-1}$ region correspond to the modes of octahedral group (Osite) of ferrites [30].
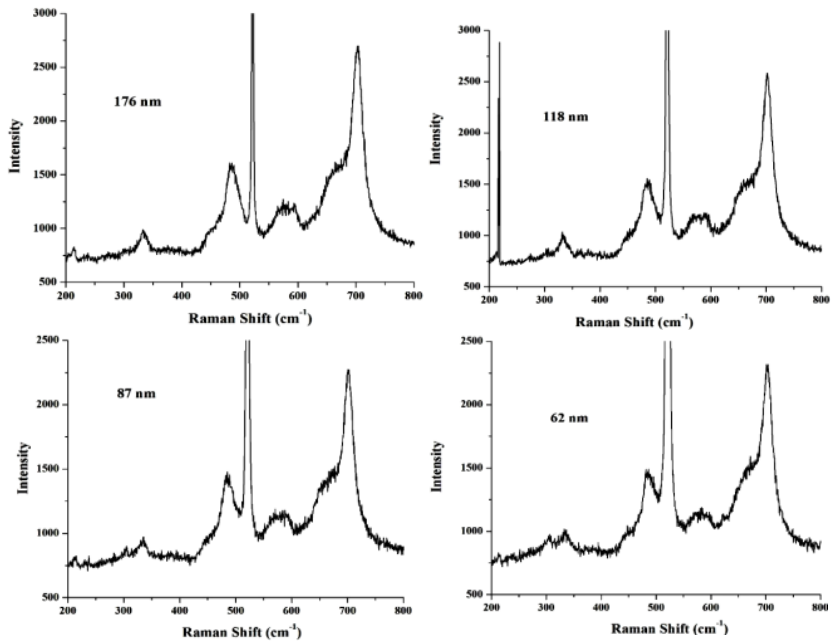

Fig. 5. Raman spectra of the films of different thickness.

The Raman peaks of O-site $\left(574 \mathrm{~cm}^{-1}\right)$ and T-site (702 $\mathrm{cm}^{-1}$ with shoulder at $666 \mathrm{~cm}^{-1}$ ) are fitted with Lorentzian line shape to get information about the cation migration. The fitted full width at half maxima is plotted as a function of thickness and is shown in Fig. 6. For $702 \mathrm{~cm}^{-1}$ all the films have similar full width at half maxima (FWHM) except film of thickness $87 \mathrm{~nm}$ that has smallest FWHM value and for the shoulder at $666 \mathrm{~cm}^{-1}$ the FWHM decreases with increase in thickness. For O-site, FWHM increases with decrease in thickness (except $87 \mathrm{~nm}$ thick film). The change in FWHM may be due to change in grain size or change in cation distribution between $\mathrm{T}$ - site and $\mathrm{O}$ site $[\mathbf{2 7}, \mathbf{3 1}]$. Grain size values reveal that it is not too small to show phonon confinement or to affect FWHM of Raman peaks. Thus cation redistribution may be responsible for the observed behaviour of FWHM with thickness. Therefore, we may conclude that cation distribution is not same for all the films but changes with thickness. This cation inversion affects the magnetic interaction between the ions and hence the magnetic properties will also be affected with thickness.
Table 2. Raman band positions for nickel ferrite thin films of different thickness.

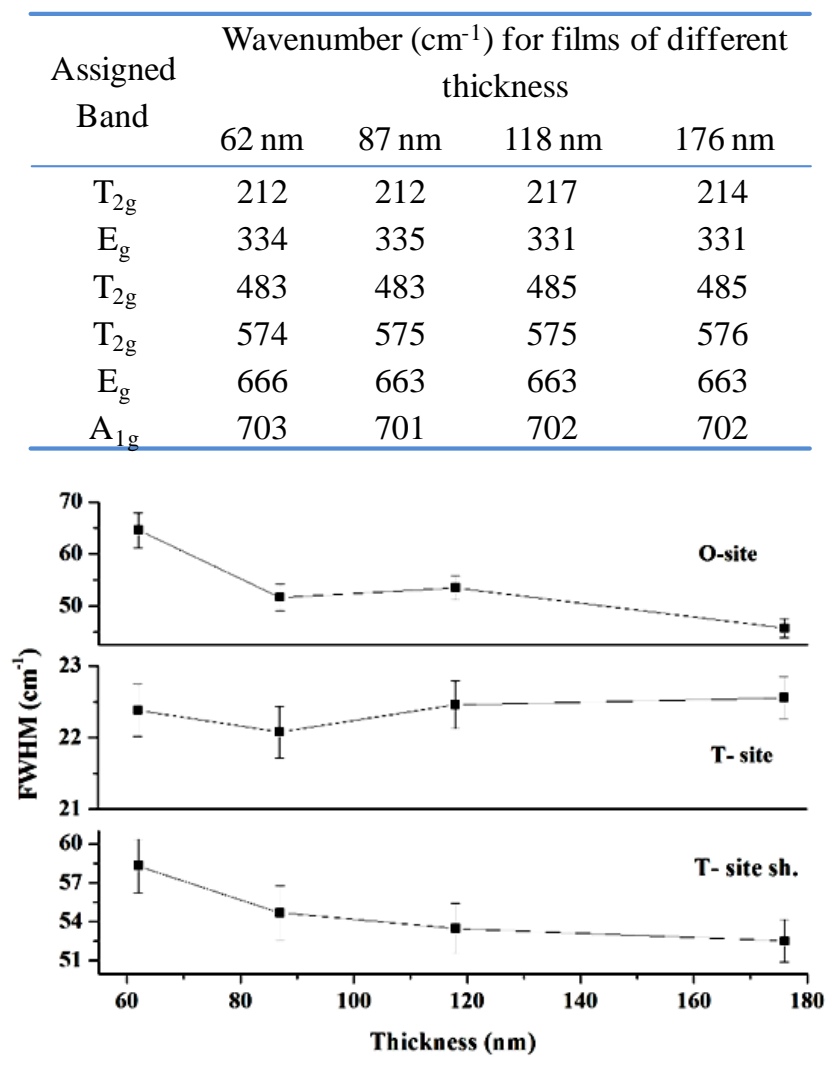

Fig. 6. Variation of FWHM of Raman peaks for different thickness films.

\section{Magnetic Study}

Hysteresis curves for all the films were recorded at $10 \mathrm{~K}$ and $300 \mathrm{~K}$ in order to see the effect of thickness on magnetic properties (Fig. $7 \&$ 8). At room temperature the coercivity of the films are extremely small so we did not go for the complete cycle. The plots at $10 \mathrm{~K}$ revealed that the coercivity of the films increases as the thickness decreases. Low roughness and high coercivity are required for technological applications [32]. From the plots, it is observed that the magnetisation does not saturate even up to a field of $2 \mathrm{~T}$ for all the films. To determine the value of saturation magnetisation, we have plotted a graph between $1 / \mathrm{H}$ and $\mathrm{M}$ for high field region $(1.5-2 \mathrm{~T})$ and fitted the following equation [33].

$$
\mathrm{M}=\mathrm{M}_{\mathrm{s}}(1-\mathrm{a} / \mathrm{H})
$$

The plot is a straight line whose intercept on $1 / \mathrm{H}=0$ axis gives the value of saturation magnetisation $\left(\mathrm{M}_{\mathrm{s}}\right)$. The estimated values of saturation magnetisation and coercivity $\left(\mathrm{H}_{\mathrm{c}}\right)$ for all the films are given in Table 3 and follow the Brown's relation [34]

$$
H_{c}=\frac{2 k_{1}}{\mu_{o} M_{s}}
$$

where $\mathrm{k}_{1}$ is anisotropy constant and $\mu_{\mathrm{o}}$ is Bohr magnetron. According to this the coercivity is inversely proportional to magnetisation. It is observed that the coercivity decreases 
from 1047 to 430 Oe with increase in thickness from 62 to $176 \mathrm{~nm}$. This is because as thickness increases the grain size increases and therefore grain boundaries decrease. Grain boundaries act as pinning sites, therefore coercivity decreases with increasing thickness [35].The saturation magnetisation for $176 \mathrm{~nm}$ thickness film is $255 \mathrm{emu} / \mathrm{cc}$ at $300 \mathrm{~K}$. This value is larger than $183 \mathrm{emu} / \mathrm{cc}$ obtained by O.F. Caltum [36] and $220 \mathrm{emu} / \mathrm{cc}$ obtained by $\mathrm{N}$. Chinnasamy et al. [11] for the as deposited films of thickness $(1.4 \mu \mathrm{m})$. At $10 \mathrm{~K}$, the $176 \mathrm{~nm}$ thickness film give saturation magnetisation $263 \mathrm{emu} / \mathrm{cc}$. This value is close to the bulk value (300 emu/cc) [37].

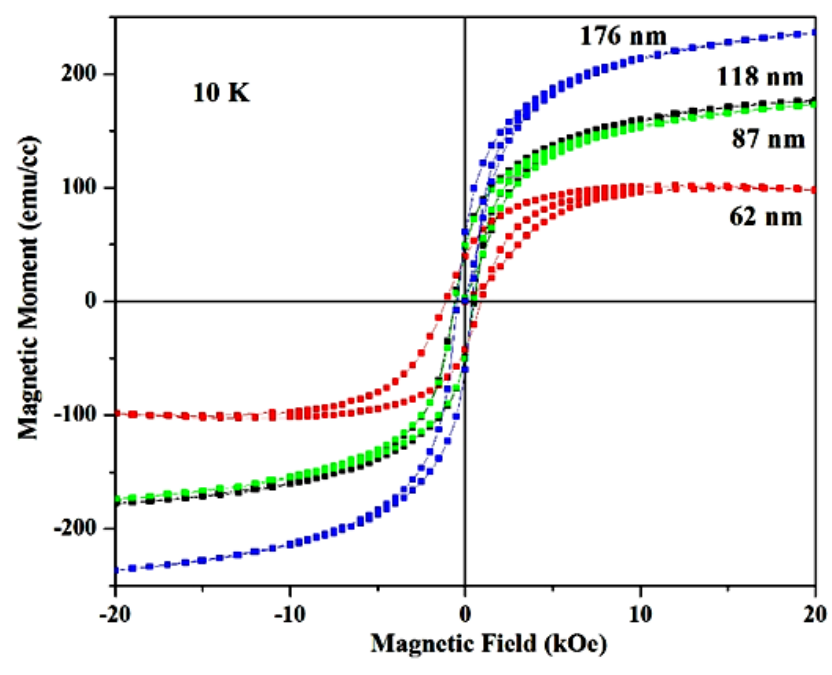

Fig. 7. Hysteresis curves at $10 \mathrm{~K}$ for the films of different thickness.

Table 3. Coercivity $\left(\mathrm{H}_{\mathrm{c}}\right)$ and saturation magnetization $\left(\mathrm{M}_{\mathrm{s}}\right)$ of the films.

\begin{tabular}{cccc}
\hline \multirow{2}{*}{ Thickness $(\mathrm{nm})$} & \multicolumn{2}{c}{$10 \mathrm{~K}$} & $\begin{array}{c}300 \mathrm{~K} \\
\end{array}$ \\
& $\mathrm{H}_{\mathrm{c}}(\mathrm{Oe})$ & $\mathrm{M}_{\mathrm{s}}(\mathrm{emu} / \mathrm{cc})$ & $\mathrm{M}_{\mathrm{s}}(\mathrm{emu} / \mathrm{cc})$ \\
\hline 62 & 1047 & 110 & 127 \\
87 & 575 & 195 & 213 \\
118 & 563 & 197 & 199 \\
176 & 430 & 263 & 255 \\
\hline
\end{tabular}

At $10 \mathrm{~K}$ the magnetisation is found to increases with thickness while at $300 \mathrm{~K}$ film of $87 \mathrm{~nm}$ thickness have saturation magnetisation higher than that for film of $118 \mathrm{~nm}$ thickness. The $118 \mathrm{~nm}$ thickness film has $\mathrm{Fe}_{2} \mathrm{O}_{3}$ phase as confirmed by XRD. $\mathrm{Fe}_{2} \mathrm{O}_{3}$ is antiferromagnetically coupled and hence depress the magnetisation [38]. Further, magnetisation decreases with increase of temperature due to thermal agitation but discrepancy is found for films of thicknesses 62 and $87 \mathrm{~nm}$. The magnetisation at $10 \mathrm{~K}$ is lower than that at $300 \mathrm{~K}$. This discrepancy begins to disappear as thickness increases because the $118 \mathrm{~nm}$ thick film has almost same magnetic moment at 10 and $300 \mathrm{~K}$ and $176 \mathrm{~nm}$ thick film has higher magnetic moment at $10 \mathrm{~K}$ than that at $300 \mathrm{~K}$ i.e similar to the trend observed in bulk materials. The magnetic moment of $176 \mathrm{~nm}$ thick film is close to that of bulk nickel ferrite. The discrepancy in lower thickness film can be explained by the modified Bloch law that explains the decay of saturation magnetisation at low temperature [39] for nanoparticles and for higher thickness film the Bloch law for bulk material is followed. Further, the anisotropy also plays an important role in affecting magnetic properties. There are various possible reasons that are known to cause magnetic anisotropy in the films like magneto crystalline structure of the material and texturing, stress developed during growth of the film, grain size (crystllanity) etc. Out of which magnetocrysatlline anisotropy is an intrinsic property of a magnetic material independent of grain size and shape. Presently the films do not have any textured growth so anisotropy caused by magnetocrystalline structure is not expected. Next, due to stress the magnetisation vector attempts to orient itself to minimize the stress energy. Since the overall domain structure is affected by the presence of stresses it affects the shape of hysteresis loop and its associated parameters. In polycrystalline films owing to randomly oriented micro stresses there may be many localised regions in which the anisotropy is uniaxial. It may give rise to overall uniaxial resultant stress [40]. During magnetisation it could impede domain wall moment and magnetisation values. Magnetic properties are also affected by grain size. Due to pinning of magnetisation at the grain boundaries $\mathrm{H}_{c}$ increases as the grain size decreases. The presence of $\mathrm{Ni}^{+2}$ ion at tetrahedral site (as confirmed by FTIR and Raman) also produces anisotropy [41]. Hence in the present case, the combined effect of anisotropy caused by grain size, stress and cation inversion is observed in films of different thickness.

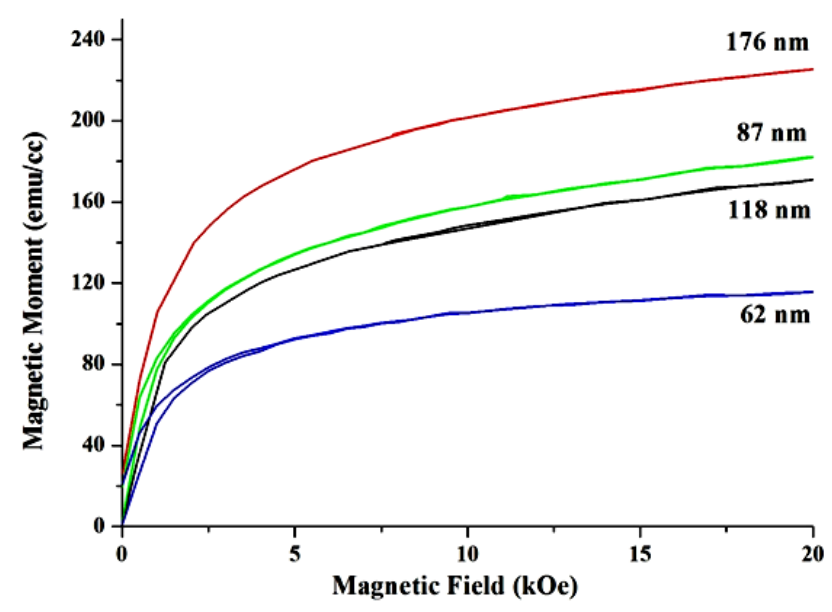

Fig. 8. M-H curve at $300 \mathrm{~K}$ for for the films of different thickness.

\section{Optical study}

Optical properties are studied by UV -vis spectra. Since the substrate $\mathrm{Si}$ is not transparent in the UV-vis region, the spectra was recorded in the reflection mode (Fig. 9) rather than transmission (or absorbance) mode. From reflectance the absorption index (k) and refractive index (n) were calculated by using the formula [42]

$$
n(\lambda)=\frac{1-R(\lambda)}{1+R(\lambda)-2 \sqrt{R(\lambda)} \cos (\theta(\lambda))}
$$




$$
k(\lambda)=\frac{-2 \sqrt{R(\lambda)} \sin (\theta(\lambda))}{1+R(\lambda)-2 \sqrt{R(\lambda)} \cos (\theta(\lambda))}
$$

where $\mathrm{R}$ is the reflectance, $\lambda$ is the wavelength; $\theta$ is the phase shift angle of the sample. The calculation was simplified making a program in $\mathrm{C}$ language. From the absorption index the absorption coefficient $\alpha$ was estimated by the relation $\mathrm{k}=\alpha \lambda / 4 \pi$. Once we have $\alpha$, the optical band gap can be easily determined from Tauc's relation $[43]$ given by

$\alpha h v=A\left(h v-E_{g}\right)^{n}$

where A is a constant that depends on the transition probability, hv is energy of incident photon, and $\mathrm{n}$ is an index that characterizes the optical absorption process and is theoretically equal to 2 or $1 / 2$ for allowed indirect or direct transition and 3 or $3 / 2$ for forbidden indirect or direct transition probability.

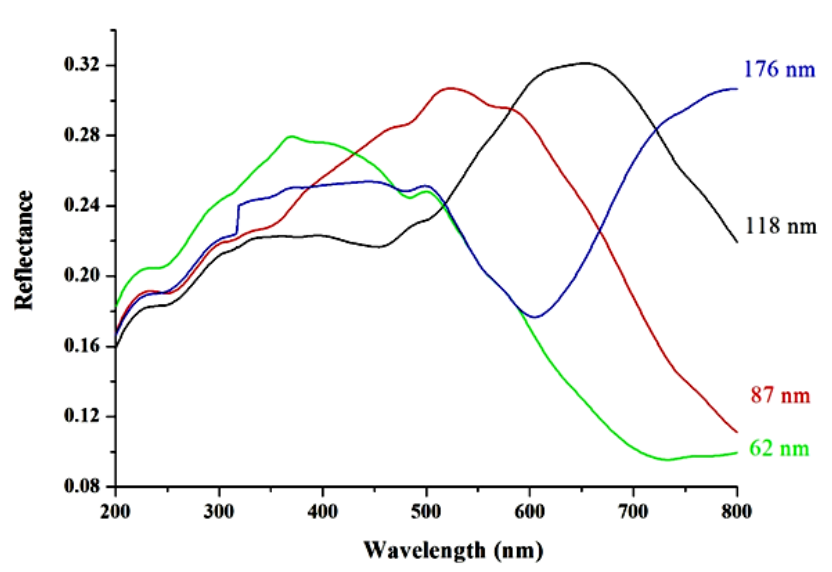

Fig. 9. UV-Vis spectra for the films of different thickness.

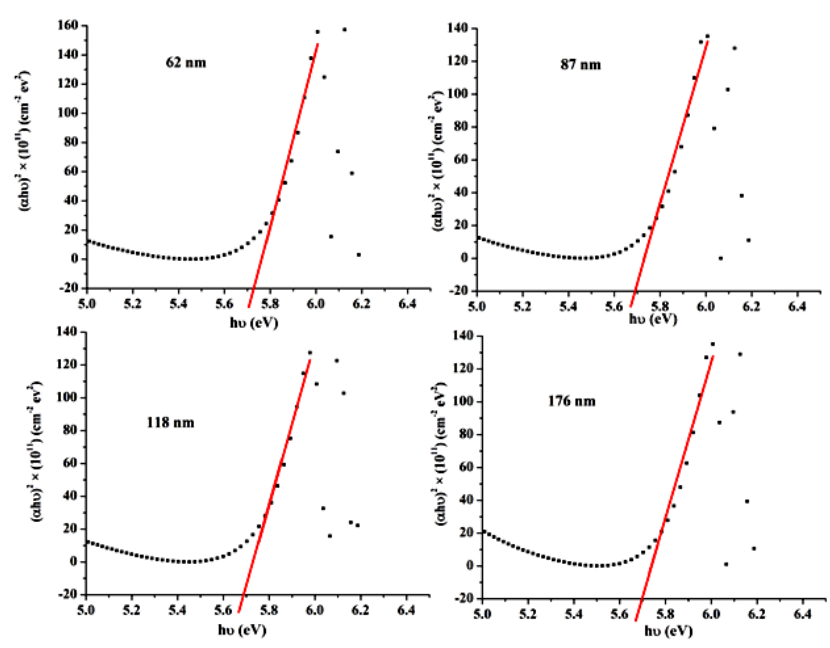

Fig. 10. Plot of $(\alpha h v)^{2}$ as a function of photon energy (eV).

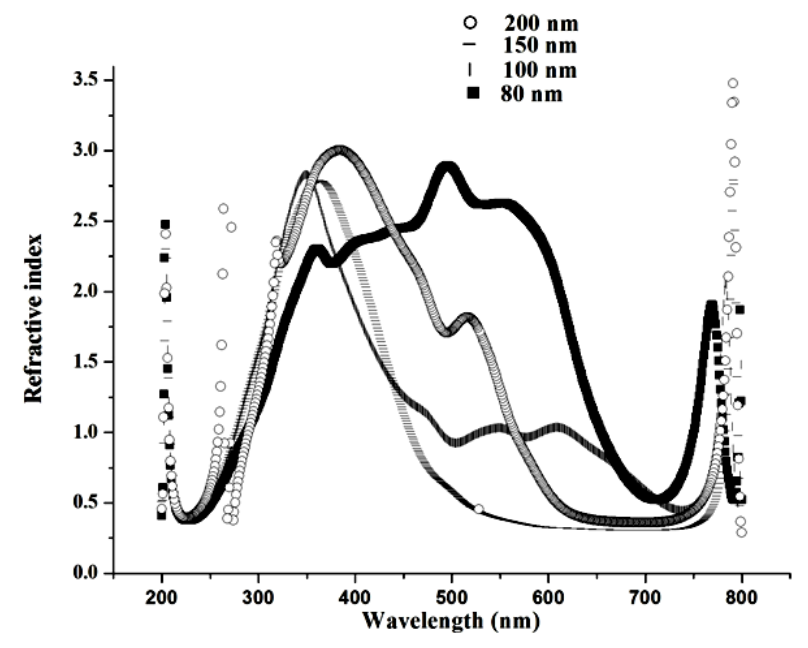

Fig. 11. Variation of refractive index with wavelength for all the films.

A straight line is obtained by plotting $(\alpha h v)^{1 / n}$ vs. hv. The intersection of this straight line on $\mathrm{x}$-axis gives the value of optical band gap. Presently the best fit is obtained for $n=1 / 2$ (Fig. 10). The value of band gap $(5.7 \mathrm{eV})$ does not change with thickness. It has been observed by others [44] also that the band gap does not change significantly with thickness after the film grows completely. A.M. Bakry [45] observed that the band gap becomes saturated for a particular value of thickness. Presently the value of optical band gap for nickel ferrite thin films is larger than $5.1 \mathrm{eV}$ reported for nickel ferrite nanoparticles [13] and $1.55 \mathrm{eV}$ reported for nickel ferrite thin films [14]. Fig. 11 shows the variation of refractive index with wavelength for different thickness of films. The refractive index dispersion plays an important role in the research of optical materials, because it is a significant factor in optical communication and in designing devices for spectral dispersion.

\section{Conclusion}

Nickel ferrite thin films of different thickness deposited on silicon substrate show polycrystalline nature. Thickness determined by XRR and surface profilometer comes out to be of the same order. XRD and Raman spectroscopy both confirm the presence of trace amount of $\alpha-\mathrm{Fe}_{2} \mathrm{O}_{3}$ in 62 and $87 \mathrm{~nm}$ thick films. FTIR shows the mixed spinel nature of nickel ferrite. Raman spectroscopy also confirms that the distribution of cations between the tetrahedral and octahedral sites is not same for all the films. Magnetic measurement shows that magnetisation increases while coercivity decreases with increase of thickness. High value of magnetisation is obtained without annealing, in comparison to other reported works. At $10 \mathrm{~K}$, the magnetisation comparable to the bulk value is obtained. Anisotropy induced by cation inversion, stress and grain size that change with thickness, is responsible for observed magnetic behaviour. Finally, we may conclude that the film thickness is an important parameter relevant to the morphology of the film and magnetic properties of the films are strongly affected by anisotropy.

\section{Acknowledgements}

Authors are thankful to Prof. Ajay Gupta, Dr. Alok Banerjee, Dr. Vasant G. Sathe, and Mr. Despande and for providing the experimental facilities 
at UGC-DAE CSR Indore. Two of the authors GD and JPS are thankful to UGC and CSIR for providing Senior Research Fellowship. Mr. Sudesh Sharma, IIT Delhi is acknowledged for fruitful discussion related to optical analysis.

\section{Reference}

1. Nakano, M.; Tomohara, K.; Song J. M.; Fukunaga H. J.Appl. Phys. 2000, 87,6217 .

DOI: $10.1063 / 1.372659$

2. Gunjakar, J.L.; More, A.M.; Shinde, V.R.; Lokhande, C.D., J.Alloy and Compounds 2008, 465,468

DOI: $10.1016 /$ j.jallcom.2007.10.130

3. Williams, C.M.; Chrisey, D.B.; Lubitz, P.; Grabowski K.S.; Cotell, C.M.; J.Appl.Phys. 1994, 75, 1676.

DOI: $10.1063 / 1.356353$

4. Phillips, J.M.; van-Dover R.B.; Gyorgy E.M.; Marshall, J.H.; Mechanism of Thin Film Evolution in: Yalisov, S.M.; Thompson, C.V.; Eagleshan, D.J. (Eds.), Mater.Res.Soc.Symp.Proc., Pittsburg, PA, 1994, 317, 87.

5. Zhou, Z-J; Yan, J.J., J.Magn.Magn. Mater. 1992, 115, 87.

DOI: $10.1016 / 0304-8853(92) 90186-\mathrm{R}$

6. van-Dover, R.B.; Venzke, S.; Gyorgy, E.M.; Siegrist, T.; Phillips, J.M.; Marshall, J.H.; Felder, R.J., Epitaxial Oxide Thin Films and Heterostructures, in: Fork, D.K. Phillips, J.M.; Ramesh, R.; Wolf R.M. (Eds.), Mater.Res.Soc.Symp.Proc. Pittsburg, PA, 1994, 341, 41.

7. Kado T., J.Appl.Phys.2006, 100, 053906.

DOI: $10.1063 / 1.2244376$

8. Dorsey, P.C.; Bushnell, S.E.; Seed, R.G.; Victoria, C., J.Appl.Phys. 1993, 74, 1242.

DOI: $10.1063 / 1.354927$

9. Samarasekara, P.; Rani, R.; Cadieu, F.J., J.Appl.Phys. 1996, 79, 5425.

DOI: $10.1063 / 1.362327$

10. Venzke., S.; Van-Dover, R.B.; Phillips., J.M; Gyorgy, E.M.; Siegrist, T.; Chen, $\quad$ C.H.; Werder, D.; Fleming., R.M; Felder., R.J.; Coleman E.; Opila, R.; J.Mater. $\quad$ Res. 1996, 11, 1187. DOI: $10.1557 / J M R .1996 .0153$

11. Chinnasamy, C.N.; Yoon, S.D.; Yang, A.; Baraskar, A.; Vittoria, C.; Harris, V.G., J.Appl.Phys. 2007, 101, 09M517. DOI: $10.1063 / 1.2714204$

12. Lŭders, U.; Bibes, M.; Bobo., J.F; Cantoni., M.; Bertacco R.; Fontcuberta, J., Phy.Rev.B 2005, 71, 134419.

DOI: $10.1103 /$ PhysRevB.71.134419

13. Srivastava, M.; Ojha, A. K.; Chaubey S.; Materny, A., J.Alloys and Compounds, 2009, 481, 515.

DOI:10.1016/j.jallcom.2009.03.027

14. Chavan,S.M.; Babrekar,M.K.; More, S.S. and Jadhav,K.M. J.Alloy \& Comp.2010 21, 507.

DOI:10.1016/j.jallcom.2010.07.171

15. Dixit, G.; Singh, J.P.; Srivastava, R.C.; Agrawal, H.M.; Choudhary, R.J.; Gupta, A., Surf. Interface Anal. 2010, 42,151. DOI: $10.1002 /$ sia.3195.

16. Pawar, S.H.; Patil, P.S.; Madhale, R.D., Lokhande, C.D., Indian J.Pure \& Appl.Phys. 1989, 27, 227.

17. Wang, X., Chen, X.; Ma, X.; Zheng, H.; Ji, M.; Zhang, Z.,Chem. Phys. Lett. 2004, 384, 391.

DOI:10.1016/j.cplett.2003.12.074

18. Leu, F.; Yang, C.; Ren, T.; Wang, A.Z.; Yu, J.; Liu L., $\begin{array}{lll}\text { J.Magn.Magn.Mater. } & \mathbf{2 0 0 7}, & 309,75 .\end{array}$ DOI:10.1016/j.jmmm.2006.06.014

19. Blombergen, N.; Laser ablation mechanism and applications II. Second international conference Knoxville, April 1993, Ed. by John C.Miller and David B. Geohegan, Aip New York, 1994,

20. Pulsed laser deposition of thin films, ed.by Douglas B.Chrisey and Graham K.Hubler, John Willey \& Sons, Inc. New York (1994)

21. Young-Yeal S., Grinolds, M. S.; Krivosik, P.; Patton, C. E., J. App. Phy. 2005, 97, 103516.

DOI:10.1063/1.1897833

22. Cheng, F.; Peng, Z.; Xu, Z.; Liao, C.; Yan, C., Thin Solid Films 1999, 339, 109 . DOI: $10.1016 /$ S0040-6090(98)01159-6

23. Shebanova, O. N. ; Lazer, P., J.State Chem. 2003, 174, 424. DOI:10.1016/S0022-4596(03)00294-9

24. Julien, C.M.; Gendron, F.; Amdouni, A.; Massot, M.; Mat. Sci Eng.B 2006, 130, 41 .

DOI:10.1016/j.mseb.2006.02.003
25. Mazen, S. A., Mat. Chem and Phy. 2000, 62,131. DOI:10.1016/S0254-0584(99)00154-6

26. Stubican, V.;Roy, R. ; Z. Kristallogr. 1961, 115, 200. DOI: $10.1524 /$ zkri.1961.115.3-4.200

27. Graves, P.R.; Johnston, C.; Campaniello, J.J., Mat.Res.Bull. 1988, 23,1651 . DOI: $10.1016 / 0025-5408(88) 90255-3$

28. Vasic, M.V. ; Antic, B.; Kremenovic, A. ; Nikolic, A.S. ; Stoiljkovic, M. ; Bibic, N.; Spasojevic, V. ; Colomban, P., Nanotechnology, 2006, 17,4877 . DOI: $10.1088 / 0957-4484 / 17 / 19 / 017$

29. Thierry, D.; Persson, D. ; Leygraf, C. ; Boucherit, N.; Goff, Hugotle., Corrosion Science, 1991, 32, 273. DOI:10.1016/0010-938X(91)90073-X

30. Zhou, Z. H.; Xue, J. M.; Wang, J.; Chan, H. S. O.; Tu, T., Shen, Z. X., J.Appl. Phys. 2002, 91, 6015. DOI: $10.1063 / 1.1462853$

31. Yu, T.; Shen, Z.X.; Shi, Y. ; Ding, J., J.Phys. : Cond. Matter. 2002 14, L613 DOI: $10.1088 / 0953-8984 / 14 / 37 / 101$

32. Tailhades, P. ; Bouet, L.; Presmanes, L. ; Rousset, A., J.Phys.France 1997, 7, C1-691. DOI: $10.1051 / \mathrm{jp} 4: 19971283$

33. Chrisey, D. B.; Hubler, G. K., Pulsed Laser Deposition Of Thin Film, John Willey \& Sons, New York.

34. Patange, S.M., Shirsath, S.E., Toksha, B.G.; Jadhav, S.S.; Jadhav, K.M., J.App.Phy. 2009, 106, 023914. DOI:10.1063/1.3176504

35. Gupta,N.; Verma,A.; Kashyap,S.C. and Dube, D.C., J. Magn. Magn. Mater. 2007, 308, 137.

DOI:10.1016/j.jmmm.2006.05.015

36. Caltum, O.F., J.Opt. Adv. Mat., 2004, 6, 935 http://joam.inoe.ro/arhiva/pdf6_3/Caltun.pdf

37. Zhou, Z.H.; Wang, J. ; Xue, J.M.; Chan, H.S.O., J Mater Chem 2001 , 11,3110 . DOI:10.1039/B105427A

38. Korenivski, V. ; van-Dover, R.V.; Suzuki, X.; Gyorgy, E.M. ; Phillips, J.M.; Felder, R.J.; J App Phy 1996, 79, 5926. DOI: $10.1063 / 1.362173$

39. Maaz, K.; Mumtaz, A.; Hasanain, S.K.; Bertino, M.F., J.Magn Mag. Mat. 2010, 322, 2199.

DOI: $10.1016 / j . j m m m .2010 .02 .010$

40. Prashanthi, K.; Duttagupa, S.P.; Pinto, R.; Palkar, V.R., Proceeding of Fourteenth International Workshop on the Physics of semiconductor Devices (IWPSD) held at IIT Bombay, p 933-935.

41. Desai, M. ; Prasad, S.; Venkataramani, N.; Samajdar, I.; Nigam, A. K.; Keller, N.; Krishnan, R.; Baggio-Saitovitch, E. M.; Pujada, B R.; Rossi, A., J. Appl. Phys. 2002, 91, 7592 DOI: $10.1063 / 1.1447504$

42. Kavak, H.; Eker, S.; Mamedov, A.; J.Quan.Spec \& Rad.Transf. 2004, 86, 223. DOI: $10.1016 /$ j.jqsrt.2003.12.002

43. Sharma, S. K.; Kumar, L.; Kumar, S.; Sharma, T. P., Chalcogenide Lett. 2008, 5,73 http://www.chalcogen.infim.ro/CdSe11.pdf

44. Jain, A.; Sagar,P.; Mehra,R.M.; Material Science Poland, 2007, 25 , 233 http://materialsscience.pwr.wroc.pl/bi/vol25no1/articles/ms_2006_04 1.pdf

45. Bakry, A.M., Egypt. J. Solids, 2008, 31, 11. http://www.arjournals.info/article.php?art id=1234 


\section{AdvanCed Materials Letters}

\section{Publish your article in this journal}

ADVANCED MATERIALS Letters is an international journal published quarterly. The journal is intended to provide top-quality peer-reviewed research papers in the fascinating field of materials science particularly in the area of structure, synthesis and processing, characterization, advanced-state properties, and applications of materials. All articles are indexed on various databases including $\underline{D O A J}$ and are available for download for free. The manuscript management system is completely electronic and has fast and fair peer-review process. The journal includes review articles, research articles, notes, letter to editor and short communications.

Submit your manuscript: http://amlett.com/submitanarticle.php 